\title{
A study of Growth Mechanism of Fe Nanowires and Nanotube via Template-Based Electrodeposition
}

\author{
Aiman Mukhtar ${ }^{1}$, Babar Shahzad Khan ${ }^{2}$, and Tahir Mehmood ${ }^{1, *}$ \\ ${ }^{1}$ The state key laboratory of Refractories and Metallurgy, Hubei Collaborative Innovation Center for \\ Advanced Steels, International Research Institute for Steel Technology, Wuhan University of Science \\ and Technology, Wuhan, P. R. China \\ ${ }^{2}$ Department of Physics, Government College Women University, 51310, Sialkot, Pakistan \\ *E-mail: tahir10621@yahoo.com, aleeza.mukhtar@yahoo.com
}

doi: $10.20964 / 2017.05 .82$

Received: 22 November 2016 / Accepted: 17 March 2017 / Published: 12 April 2017

\begin{abstract}
Highly ordered Co nanowire and nanotube arrays were fabricated using anodic aluminum oxide (AAO) templates by DC electrodeposition technique.The Fe microstructures and growth mechanism were investigated using conventional transmission electron microscopy(TEM),Scanning electron microscopy (SEM),X ray diffraction(XRD) method. Two templates with pore size $\sim 50 \mathrm{~nm}$ and $\sim 100$ $\mathrm{nm}$ was prepared, for deposition of nanowires and nanotubes. The material of working electrode and its effect on growth of nanowires and nanotubes was discussed. Our proposed factors i.e. the material of working electrode, $\mathrm{pH}$ value, pore diameter and the concentration of metal ions in electrolyte can be useful in future to compose and synthesize other metal nanostructures via template-based electrodeposition.
\end{abstract}

Keywords: Crystal structure; Nucleation; Growth from solutions; Deposition parameters;

\section{$\underline{\text { FULL TEXT }}$}

(C) 2017 The Authors. Published by ESG (www.electrochemsci.org). This article is an open access article distributed under the terms and conditions of the Creative Commons Attribution license (http://creativecommons.org/licenses/by/4.0/). 